\title{
The changing synoptic origins of Irish precipitation
}

\author{
JOHN C. SWEENEY \\ Lecturer in Geography, St. Patrick's College, Maynooth, Co. Kildare, Ireland
}

Revised MS received 19 September, 1985

\begin{abstract}
Using Lamb circulation categories, daily precipitation receipt for 34 Irish sites are examined for the period since 1941. Marked gradients are apparent with particular trajectories, and the influence of ocean surface temperatures and topography is described. Changes in the frequency of occurrence of synoptic types, particularly westerly and cyclonic categories, are shown to have implications for the national distribution of precipitation and also for particular areas in terms of annual receipt.
\end{abstract}

KEY WORDS: Ireland, Precipitation, Lamb weather types, Synoptic climatology, Synoptic changes

\section{INTRODUCTION}

In terms of its ability to convert water vapour into precipitation, Ireland possesses one of the world's most efficient climatic regimes. This stems essentially from the geographical location of the island, firstly on an oceanic margin where the supply of water vapour is plentiful throughout the year, and secondly, amid the principal depression tracks of the North Atlantic. The condensation forcing mechanisms which this latter ingredient provides are further enhanced by the orographic effects of the relief configuration of Ireland where all the land above $750 \mathrm{~m}$ lies within $56 \mathrm{~km}$ of the coastline.

Despite the obvious necessity of studying precipitation climatology as a pre requisite in understanding the operation of Irish weather and climate, relatively few investigations have been made. Most, such as Morgan (1953), Dixon (1955), Rohan (1975) and Logue (1971, 1975 and 1978) have concentrated their attentions on statistical analysis of rainfall amounts, irrespective of its origin. This work has enabled a reasonably comprehensive picture of the seasonal characteristics, and extreme event return periods, to be assembled. In terms of studies seeking to relate precipitation to synoptic circulation types, however, less success is apparent. Perry (1972), Houghton and O'Cinneide (1976a) and Mills (1983) have examined spatial contrasts across Ireland in relation to specific circulation types, though often with a rather restricted time period in evidence. The purpose of this paper is first, to extend the utility of such analyses by examining rainfall patterns across Ireland using the most complete observational records available and secondly to make some preliminary comments on the impact which recent circulation changes are having in terms of Irish rainfall characteristics.

\section{SPATIAL AND SEASONAL DISTRIBUTION OF PRECIPITATION}

A brief examination of Figure 1 confirms the two principal characteristics of the annual precipitation pattern. First, the classic west to east gradient is apparent with isolated mountain locations in the west and south west receiving over $3000 \mathrm{~mm}$ annually, while parts of the Dublin area receive less than $750 \mathrm{~mm}$. Secondly, the close relationship between altitude and amount may be inferred. The precise nature of this relationship is as yet unknown, as is, for example, whether or not rainfall amounts increase to summit levels, or show regional variations in rates of altitudinal increase. Certainly, rain shadow effects can be seen in the lee of the major upland areas, for instance in the lowlands around the Foyle and along the east and south coasts. The most striking anomaly lies in Co. Limerick where conditions more akin to the eastern half of the country 


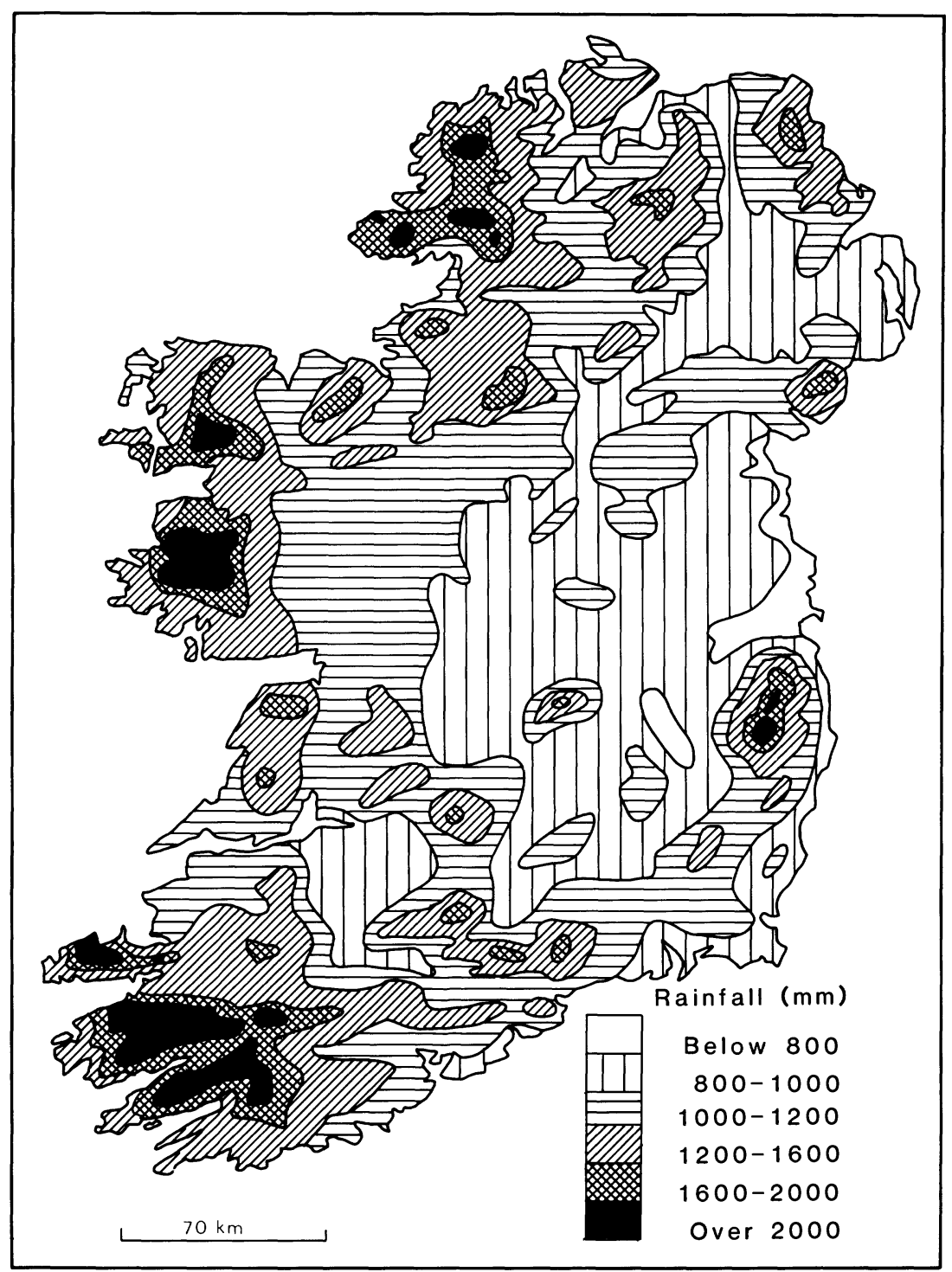

FIGURE 1. Annual average precipitation 1941-70

extend over a wide area. This is also the only location where the $1000 \mathrm{~mm}$ isohyet reaches the west coast. The sensitivity of this area, in particular, to recent circulation changes will be demonstrated later.

In beginning to explain this spatial pattern the first point which should be made is that it does not derive from west to east contrasts in rainfall intensity from similar rainfall producing events. This was demonstrated by Logue (1975) by contrasting the rainfall patterns produced by high intensity as opposed to long duration events of the same return period. A weak spatial field was apparent with high intensity precipitation and no marked west-east contrasts existed. This is in agreement with the findings of Bleasdale (1963), Glasspoole (1930) and the Meteorological Office (1975) in Britain. With long duration events, however, the converse was true and the annual precipitation relationships were mirrored to a high degree. This emphasizes the fact that it is 


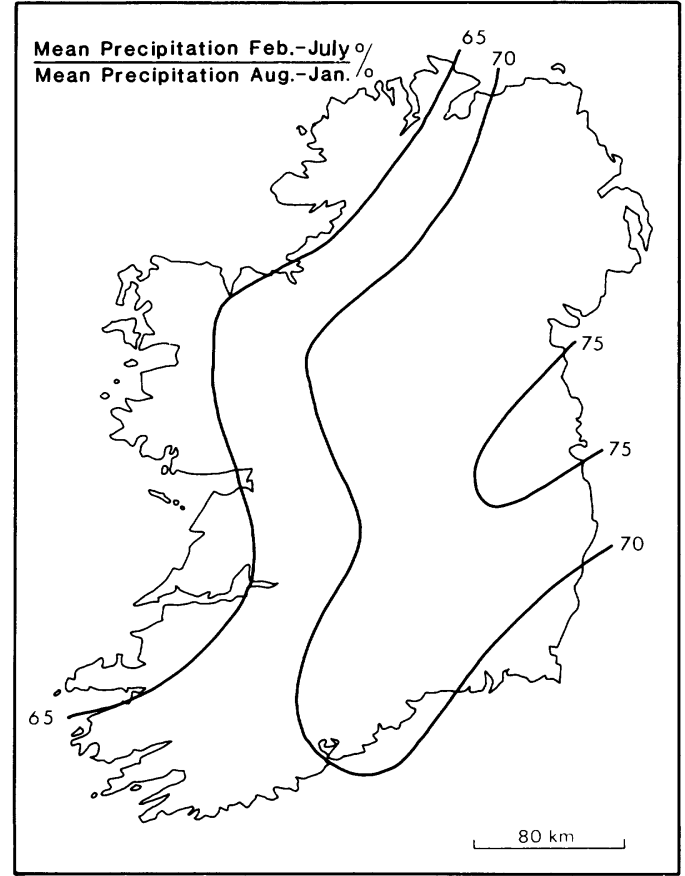

FIGURE 2. Precipitation Feb-July as a ratio of Aug-Jan more persistent precipitation, rather than a greater yield per unit time, which is responsible for producing the west-east contrast on an annual basis. Mean rainfall intensities at Claremorris (Co. Mayo) in the west, and Dublin Airport in the east, for example, are almost identical, while mean duration of rainfall at the former is over 50 per cent greater.

Some of the west-east contrast is, however, attributable to a seasonal imbalance. For most locations the period February-July is the drier half of the year. If amounts during this period are expressed as a ratio of amounts during the remainder, an index of seasonality is produced. Figure 2 shows that, by this measure, western parts have a more seasonal regime than eastern and central Ireland. This characteristic, noted by Logue (1978) is undoubtedly related to the influence of sea surface temperatures. At the Kish Bank in the Irish Sea for example, these range from $6.9^{\circ} \mathrm{C}$ in early February to $14^{\circ} \mathrm{C}$ in late August. Off the south west coast, water temperatures seldom fall below $10^{\circ} \mathrm{C}$. The temperature contrast which this creates in winter between the ocean surface and the overlying air has a dual effect. First, it triggers convective motions which move with the

TABLE I. Principal Lamb Circulation Types

Anticyclonic (A)

Cyclonic (C)

Westerly (W)

Northwesterly (NW)

Northerly (N)

Easterly (E)

Southerly (S)
Anticyclone centred over, near or extending over the British Isles; therewith also cols situated over the area, between two anticyclones.

Depression stagnating over, or frequently passing across, the British Isles. The further criterion used is that a depression should be centred, or its central isobar on a $4-5 \mathrm{mb}$ spacing should extend over the mainland of Britain or Ireland at some time during the day. Further, individual days between the passing of separate centres over the area are also counted as cyclonic if the main (surface) low pressure axis remains over the area.

High pressure to the south (also sometimes south west or south east) and low pressure to the north of the British Isles. Sequence of depression and ridges travelling eastwards across the Atlantic.

Azores anticyclone displaced north-east towards the British Isles or north over the Atlantic, or with extensions in these directions. Depressions (often forming near Iceland) travel south east or east south east into the North Sea and reach their greatest intensity over Scandinavia or the Baltic.

High pressure to the west and north west of the British Isles, particularly over Greenland and sometimes extending in a continuous belt south over the Atlantic Ocean towards the Azores. Low pressure usually over the Baltic, Scandinavia and the North Sea. Depressions move southwards or south eastwards from the Norwegian Sea.

Anticyclones over, or extending across, Scandinavia and towards Iceland. Depressions circulating over the western North Atlantic and in the Azores-Spain-Biscay region.

High pressure covering central and northern Europe. Atlantic depressions blocked west of the British Isles or travelling north or north eastwards off the western coasts. 


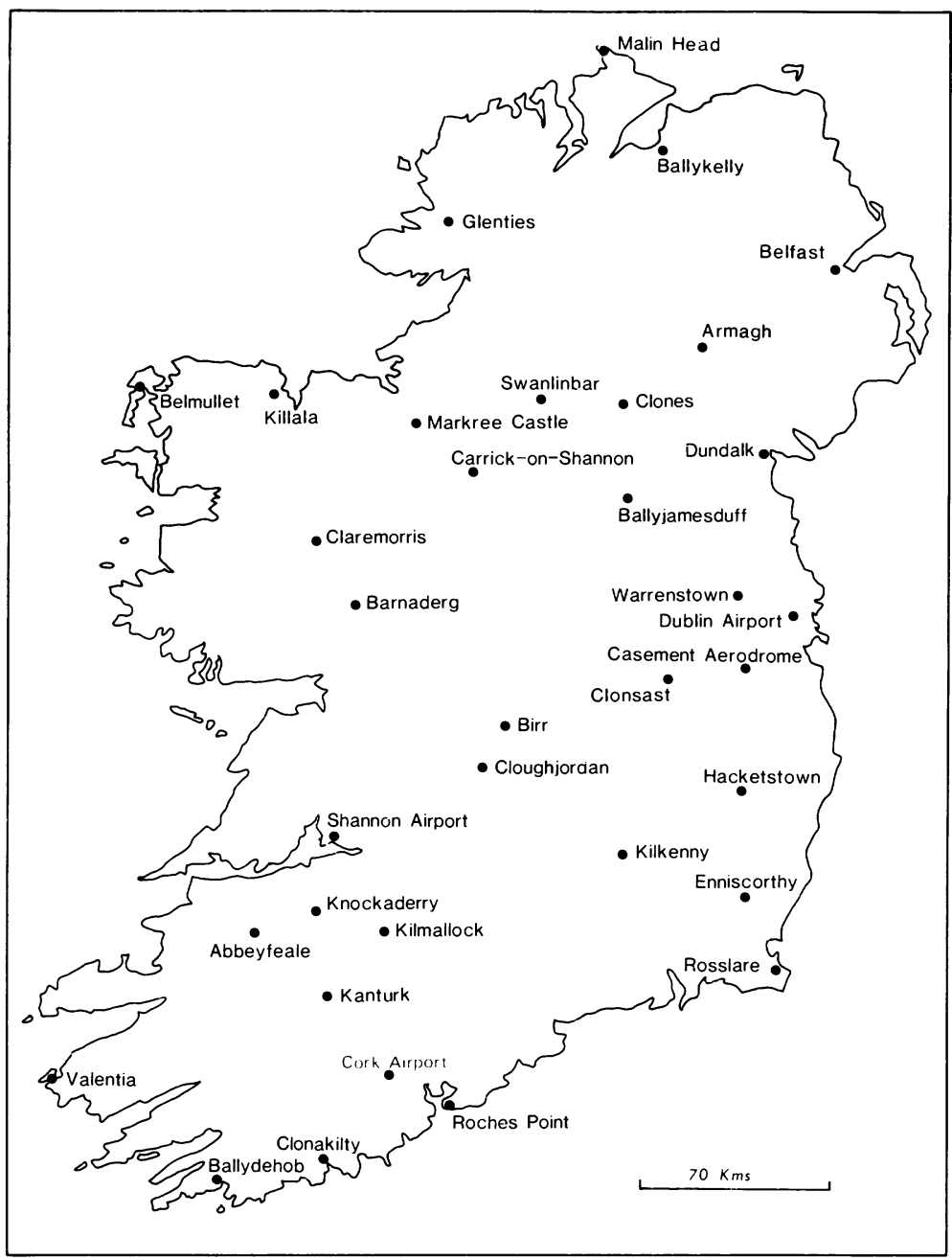

FIGURE 3. Stations employed in the analysis

westerly circulation and release the bulk of their precipitation over western parts. Secondly, it enables a transfer of sensible and latent heat to frontal systems which are rendered more active at this season in western margins. Both of these aspects are not exclusive to each other, and may be reconciled in the convective shafts which are now known to characterize frontal zones at a mesoscale level (Hobbs and Locatell, 1978). In summer, convective activity switches on to the land, and is more pronounced in the more continental east of Ireland. This area thus has a more even seasonal distribution than western areas, with more tendencies towards a summer maximum. The hundred year record from the Phoenix Park in Dublin shows August to be the wettest month, rather surprising at first sight in an island often heralded as exemplifying maritime influences par excellence.

Further complications in the rainfall pattern are hinted at by the existence also of north to south contrasts. These were noted by Morgan (1953) and Perry (1972) and are attributed to preferred depression tracks across Ireland. Such depressions may themselves exhibit considerable diversity and this will also manifest itself in spatial receipt patterns (Thomas, 1960). 
The sensitivity of Irish precipitation patterns to circulation types and frequency is thus hinted at and Perry's (1972) assertion that:

Any long term variations in the atmospheric circulation can be expected to be reflected in changes in the precipitation climatology of Ireland.

would thus seem worthy of further consideration.

\section{THE SYNOPTIC ORIGINS OF IRISH PRECIPITATION}

In relating precipitation to circulation characteristics the first requirement is for some form of daily categorization of airflow types across Ireland. This has been done according to a scheme originally devised by Lamb (1950) which involved seven primary circulation categories. In a subsequent revision a further nineteen hybrid types were added to incorporate more complex circulation types into a register extending from 1861 (Lamb, 1972). The categories are considered to be representative of an area $\left(50-60^{\circ} \mathrm{N}\right.$ and $\left.10^{\circ} \mathrm{W}-2^{\circ} \mathrm{E}\right)$ which includes the whole of Ireland although a modified register more appropriate to conditions here is currently under preparation (Betts, 1982). The criteria by which days are allocated to a particular type are well known and can be seen in Table I.

Daily rainfall values for 53 stations, for the period from 1941 onwards, were initially assembled. 1941

TABLE II. Mean Daily Precipitation (mm) by Principal Lamb Types

\begin{tabular}{|c|c|c|c|c|c|c|c|c|}
\hline & & & & Lamb Weath & ter Types & & & \\
\hline & Anticyclonic & Cyclonic & Westerly & Northwesterly & Northerly & Easterly & Southerly & Unclassified \\
\hline Ballydehob & $1 \cdot 85$ & $4 \cdot 22$ & $5 \cdot 52$ & $1 \cdot 44$ & 0.93 & 3.05 & $7 \cdot 18$ & $5 \cdot 19$ \\
\hline Clonakilty & $1 \cdot 64$ & $4 \cdot 00$ & $4 \cdot 32$ & 1.03 & 0.71 & $3 \cdot 76$ & $7 \cdot 25$ & $4 \cdot 76$ \\
\hline Roches Point & $1 \cdot 10$ & 3.55 & $3 \cdot 11$ & 0.62 & 0.53 & $3 \cdot 36$ & $6 \cdot 26$ & $4 \cdot 24$ \\
\hline Cork Airport & $1 \cdot 47$ & $4 \cdot 08$ & 3.62 & 0.84 & 0.59 & 3.59 & $8 \cdot 72$ & $5 \cdot 03$ \\
\hline Valentia & $1 \cdot 87$ & $4 \cdot 52$ & $5 \cdot 24$ & $1 \cdot 81$ & $1 \cdot 50$ & 2.06 & $9 \cdot 16$ & $5 \cdot 11$ \\
\hline Kanturk & $1 \cdot 04$ & $3 \cdot 89$ & 3.69 & $1 \cdot 69$ & 0.96 & $2 \cdot 63$ & $5 \cdot 88$ & 3.61 \\
\hline Abbeyfeale & $1 \cdot 02$ & $4 \cdot 38$ & $5 \cdot 19$ & $2 \cdot 98$ & $1 \cdot 27$ & $1 \cdot 61$ & 5.03 & 3.59 \\
\hline Kilmallock & 0.95 & $3 \cdot 84$ & $3 \cdot 36$ & $1 \cdot 64$ & 0.88 & $2 \cdot 00$ & $5 \cdot 48$ & $3 \cdot 51$ \\
\hline Knockaderry & 0.82 & $2 \cdot 80$ & $2 \cdot 05$ & 0.59 & 0.37 & 2.02 & $4 \cdot 77$ & $3 \cdot 38$ \\
\hline Kilkenny & 0.73 & 3.79 & $2 \cdot 89$ & 0.89 & 0.53 & $1 \cdot 60$ & $5 \cdot 53$ & $3 \cdot 30$ \\
\hline Clonsast & 0.60 & $3 \cdot 22$ & $2 \cdot 39$ & $1 \cdot 17$ & 0.63 & $1 \cdot 39$ & $3 \cdot 20$ & $2 \cdot 81$ \\
\hline Hacketstown & 0.85 & $4 \cdot 52$ & $3 \cdot 45$ & $1 \cdot 75$ & 1.06 & $2 \cdot 31$ & $6 \cdot 66$ & 3.93 \\
\hline Rosslare & 0.78 & $4 \cdot 05$ & $2 \cdot 98$ & 0.60 & 0.58 & $2 \cdot 20$ & $5 \cdot 57$ & $3 \cdot 74$ \\
\hline Enniscorthy & 0.86 & $3 \cdot 63$ & $2 \cdot 72$ & 0.95 & 0.60 & $2 \cdot 19$ & 6.08 & $4 \cdot 07$ \\
\hline Shannon & 0.84 & $3 \cdot 79$ & $4 \cdot 22$ & $1 \cdot 57$ & 0.71 & $1 \cdot 56$ & $4 \cdot 19$ & $3 \cdot 37$ \\
\hline Cloughjordan & 0.85 & $4 \cdot 05$ & $3 \cdot 91$ & $1 \cdot 51$ & 0.85 & $1 \cdot 60$ & $4 \cdot 42$ & 3.37 \\
\hline Birr & 0.68 & $3 \cdot 89$ & 3.51 & $1 \cdot 22$ & 0.70 & $1 \cdot 22$ & $3 \cdot 82$ & $2 \cdot 94$ \\
\hline Casement & 0.47 & $4 \cdot 27$ & $2 \cdot 61$ & $1 \cdot 07$ & 0.65 & 2.06 & $2 \cdot 75$ & $2 \cdot 59$ \\
\hline Barnaderg & $1 \cdot 19$ & $3 \cdot 78$ & $4 \cdot 93$ & $1 \cdot 76$ & $1 \cdot 10$ & $1 \cdot 59$ & $4 \cdot 92$ & 3.76 \\
\hline Claremorris & $1 \cdot 11$ & $4 \cdot 17$ & $5 \cdot 00$ & $1 \cdot 87$ & $1 \cdot 33$ & $1 \cdot 40$ & $5 \cdot 35$ & $3 \cdot 80$ \\
\hline Carrick-on Sh. & $1 \cdot 08$ & 3.93 & $4 \cdot 23$ & $2 \cdot 28$ & $1 \cdot 13$ & $1 \cdot 41$ & $4 \cdot 58$ & 3.65 \\
\hline Ballyjamesduff & 0.95 & $4 \cdot 33$ & $4 \cdot 17$ & $1 \cdot 99$ & 0.85 & $1 \cdot 77$ & $4 \cdot 49$ & $3 \cdot 45$ \\
\hline Warrenstown & 0.73 & $4 \cdot 37$ & $3 \cdot 36$ & $1 \cdot 49$ & 0.75 & $1 \cdot 99$ & $3 \cdot 45$ & $3 \cdot 24$ \\
\hline Dublin Airport & 0.52 & $4 \cdot 46$ & $2 \cdot 36$ & $1 \cdot 01$ & 0.66 & $2 \cdot 10$ & $3 \cdot 29$ & 3.03 \\
\hline Belmullet & $1 \cdot 39$ & $3 \cdot 72$ & $4 \cdot 92$ & $2 \cdot 30$ & $1 \cdot 74$ & $1 \cdot 12$ & $4 \cdot 78$ & $3 \cdot 53$ \\
\hline Killala & $1 \cdot 20$ & $4 \cdot 07$ & $5 \cdot 03$ & $2 \cdot 77$ & $2 \cdot 25$ & $1 \cdot 46$ & $4 \cdot 64$ & $3 \cdot 37$ \\
\hline Markree Castle & 1.05 & $4 \cdot 04$ & $4 \cdot 01$ & $3 \cdot 12$ & $1 \cdot 71$ & $1 \cdot 13$ & $3 \cdot 88$ & 3.04 \\
\hline Clones & 0.78 & $4 \cdot 12$ & $4 \cdot 04$ & 2.09 & 0.71 & $1 \cdot 23$ & 3.96 & $3 \cdot 24$ \\
\hline Dundalk & 0.61 & 3.06 & $2 \cdot 06$ & $1 \cdot 07$ & 0.43 & $1 \cdot 31$ & $3 \cdot 11$ & $2 \cdot 71$ \\
\hline Glenties & $1 \cdot 27$ & 3.91 & $4 \cdot 91$ & $3 \cdot 21$ & $1 \cdot 82$ & 0.77 & $4 \cdot 25$ & $3 \cdot 85$ \\
\hline Malin Head & 0.98 & $4 \cdot 05$ & $5 \cdot 18$ & $3 \cdot 16$ & $1 \cdot 65$ & $1 \cdot 04$ & 2.96 & $3 \cdot 34$ \\
\hline Armagh & 0.79 & $4 \cdot 00$ & $3 \cdot 36$ & $1 \cdot 74$ & 0.87 & $1 \cdot 49$ & $3 \cdot 62$ & $3 \cdot 00$ \\
\hline Ballykelly & $1 \cdot 22$ & $6 \cdot 14$ & $4 \cdot 91$ & $4 \cdot 84$ & $2 \cdot 22$ & $1 \cdot 53$ & $4 \cdot 61$ & 3.92 \\
\hline Belfast & 0.79 & 4.59 & $3 \cdot 77$ & $2 \cdot 15$ & 0.82 & $1 \cdot 39$ & $4 \cdot 24$ & $3 \cdot 37$ \\
\hline Mean & 1.00 & $4 \cdot 04$ & $3 \cdot 85$ & $1 \cdot 83$ & 1.00 & $1 \cdot 85$ & $4 \cdot 94$ & $3 \cdot 61$ \\
\hline
\end{tabular}




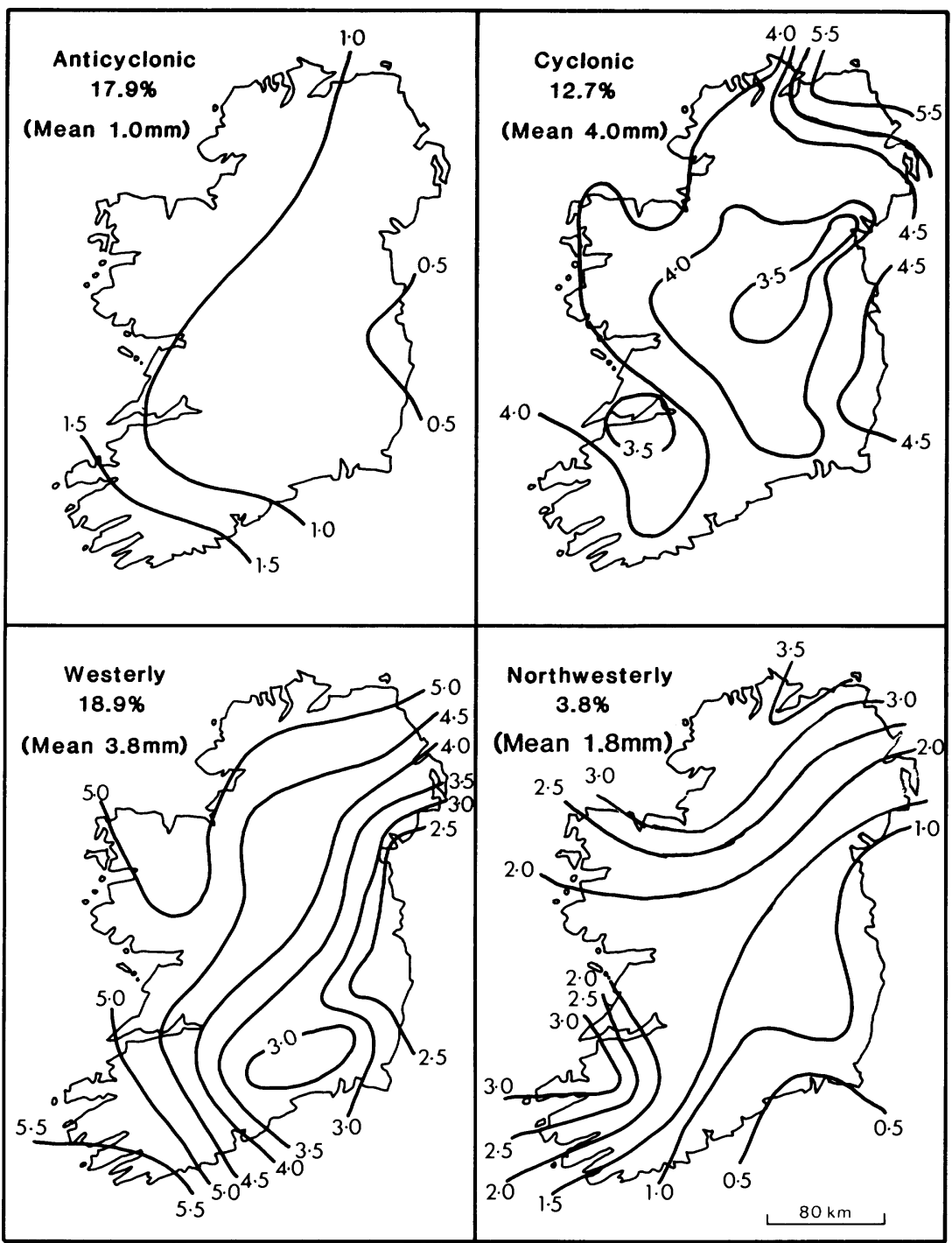

FIGURE 4. Mean Daily Precipitation receipt by Lamb category

$\begin{array}{ll}\text { (a) Anticyclonic } & \text { (b) Cyclonic }\end{array}$

$\begin{array}{ll}\text { (c) Westerly } & \text { (d) North westerly }\end{array}$

marks the commencement of records stored on disk by the Irish Meteorological Service. These stations were selected from an inspection of the complete network on the basis of their length, reliability and location. Further processing was then carried out to identify incorrectly entered data and to remove all estimated and cumulative observations. Ultimately, 35 stations were retained for analysis, although at a still later stage one further rejection was made (Swanlinbar) on grounds of possible over exposure of the site.

The network (Fig. 3) can be considered representative of conditions in lowland Ireland if it can be shown to be free of spatial bias in its geographical distribution. To investigate this a nearest neighbour index $(R)$ was calculated where: 


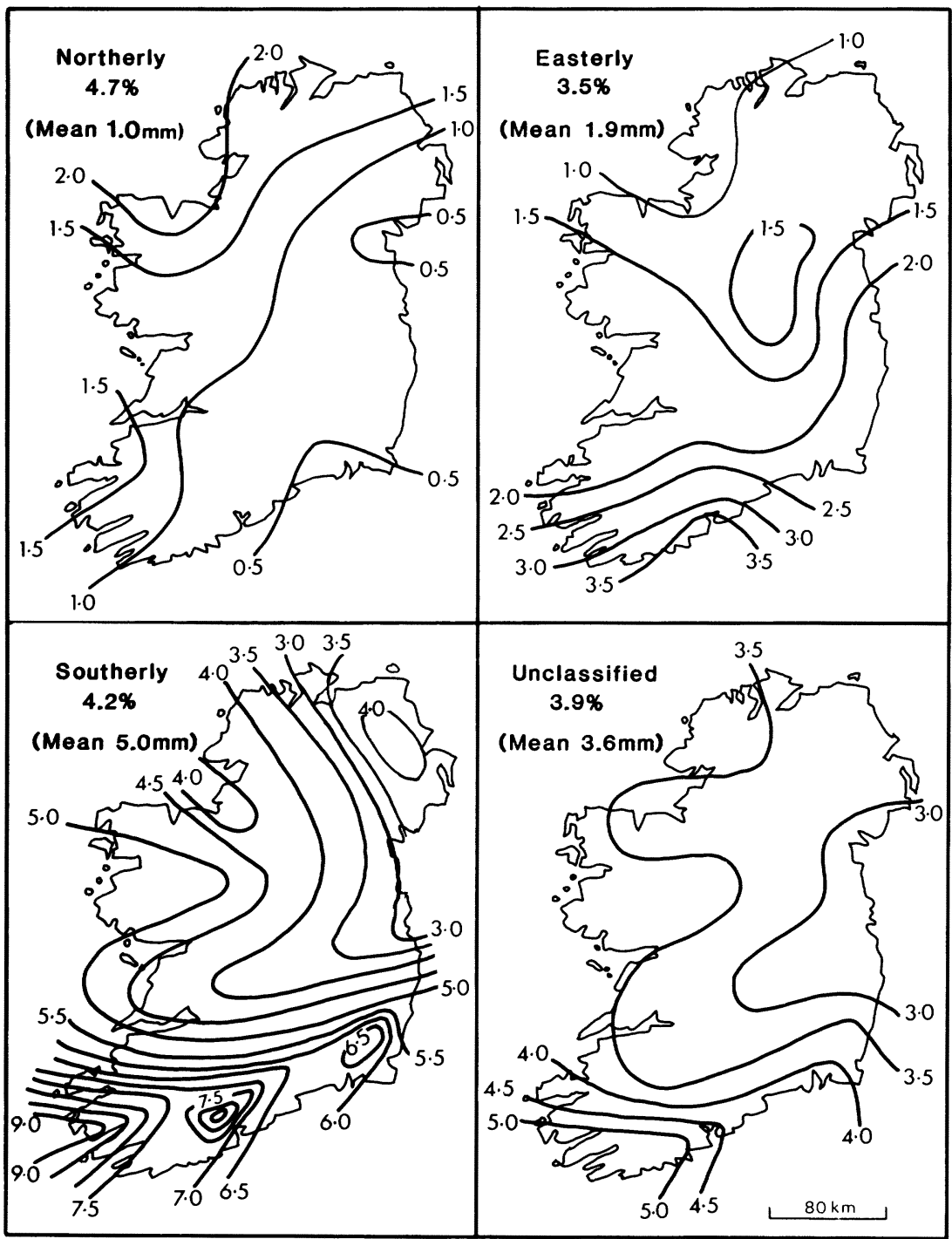

FIGURE 5. Mean daily precipitation receipt by Lamb category
(a) Northerly
(b) Easterly
(c) Southerly
(d) Unclassified

$$
\mathrm{R}=\frac{\mathrm{d}_{\mathrm{obs}}}{\mathrm{d}_{\mathrm{ran}}}
$$

where

$\mathrm{d}_{\mathrm{obs}}=$ observed mean nearest-neighbour distance

$\mathrm{d}_{\mathrm{ran}}=$ expected mean nearest-neighbour distance for a random arrangement of stations.
The nearest neighbour index varies between 0.0 , indicating a completely clustered arrangement and $2 \cdot 15$, indicating a completely dispersed pattern. A value of 1.0 indicates a random arrangement. A value for $R$ of $I \cdot 14$ was obtained, suggesting that a clustered network was not in evidence, and that the network could be considered significantly random at the 0.01 level. 
Using the full length of record from each station has the advantage also of minimizing the problems resulting from a lack of synchronization between the Lamb weather types, assigned on a midnight to midnight basis, and the daily rainfall readings, not made until $09.00 \mathrm{hrs}$ on the following morning. This lack of temporal compatibility is, however, not too serious since the Lamb classification is not designed to be used strictly to characterize airflow on a particular day in isolation, but rather to indicate the nature of a sequence of days. In fact the strongest relationships were observed when the rainfall values were not thrown back to the previous day. This suggests that the Lamb categories may not be as applicable to a westerly location such as Ireland as intended, and that they are thus better matched to the last nine hours of the rainfall day rather than the first fifteen.

Mean daily rainfall amounts for each of the twenty-seven Lamb weather types were calculated for each station. The remainder of this paper however confines itself principally to examination only of the eight primary circulation categories. The results of these calculations are seen in Table II which shows the considerable variability in rainfall yields apparent with different circulation types. A northerly airflow, for example, produces about $1 \mathrm{~mm}$ on average while a southerly flow yields almost five times this amount. The marked rainfall gradients which occur in relation to circulation trajectories is best appreciated, however, if the data are mapped (Figs 4 and 5). It should be emphasized that these maps relate only to the lowlands of which the synoptic stations are representative. No account has been taken of orographic enhancement in upland areas. The maps may, however have some utility for forecasting likely amounts or probability with particular circulation types, especially since they are based on very large sample sizes. For the major circulation categories the mean precipitation amounts were calculated from several hundred days of the particular type. For the three most frequently occurring categories (anticyclonic, cyclonic and westerly) the number of days used for calculation exceeded 2800 at some stations.

\section{Anticyclonic type (Fig. 4a)}

This type of circulation involves a high pressure area centred over or extending over the British Isles. As such, the areas closest to the centre of subsidence generally lie on the eastern half of Ireland, with the western half less dominated by high pressure influences, perhaps with Atlantic fronts skirting the western seaboard. Accordingly, a very slack east to west gradient is observed. Rainfall amounts are uniformly small, although somewhat greater, especially in the south west, than suggested by Houghton and O'Cinneide (1976a). Only along the western seaboard do amounts significantly exceed $1 \mathrm{~mm}$.

\section{Cyclonic type (Fig. 4b)}

A cyclonic circulation implies the movement of a depression centre across Ireland. Over a long period the track taken may vary, promoting again a fairly even distribution of precipitation across the country. In contrast to the findings of Houghton and O'Cinneide (1976a), however, rainfall amounts are not greatest with this circulation type, with the exception of east central Ireland and the extreme north east of Ulster, a finding corroborated by Mills (1983). A noticeable decrease in amounts can be discerned in the interior of Ireland which may be related to a less abundant supply of oceanically derived water vapour in these inland locations.

The heaviest receipt appears concentrated along the Co. Antrim coast and this suggests that the North Channel may be instrumental in producing precipitation activity with unstable north westerly airflows. This is hinted at also in the map of north westerly precipitation although further analysis would be needed to corroborate this hypothesis.

\section{Westerly type (Fig. 4c)}

A north to south pressure gradient, usually in conjunction with depression passage to the north of Ireland, produces this circulation type. The west to east decline in amounts shown is therefore to be expected, such airflows maximizing orographic influences. In the north and northwest this is the wettest airflow, with amounts typically twice as large as those received in the rain shadow east of the Wicklows. A marked rainshadow in the lee of the Cork-Kerry mountains can also be seen. Westerly airflow is also the main supplier of rainfall around the lower Shannon Basin, which is relatively exposed to in this direction. Amounts generally increase with this airflow towards the north west, an indication of the role played by the greater proximity of these areas to the depression centres at their most active stages of development.

North westerly type (Fig. 4d)

The extension northwards in mid Atlantic of the 
Azores anticyclone forces depressions to pass north of Ireland in a north west to south east direction, producing a north westerly airflow. Rainfall receipt thus shows a north-south gradient with a considerable contrast between the north and south coasts. Amounts, however, are relatively light away from north facing coasts, suggesting an important role for elevation and exposure considerations with this airflow.

\section{Northerly type (Fig. 5a)}

High pressure to the west of Ireland, with low pressure over continental Europe, produces the driest airflow as far as most of Ireland is concerned. Exposure is again the main control on amounts with northern and western areas receiving rainfall from convective showers triggered by the warming of the cold northerly flow as it traverses warmer ocean. Again a marked shadow can be discerned along the south coast and south of the Mournes.

\section{Easterly type (Fig. 5b)}

When depression tracks lie to the south of Ireland the resultant easterly flow is quite dry. Winds are predominantly blowing over land areas and have shed much of their water vapour burden over Britain. Areas in Ireland which receive significant rainfall with such circulations are, as expected, along the east and south coasts. The proximity of the south coast to the depression centres explains its relatively high totals. In the Cork area, for example, amounts may be comparable with those received on westerly or cyclonic airflows. In the north west however, less than $1 \mathrm{~mm}$ is typical. A notable extension of this relatively dry area exists into the area to the west of the Wicklows where shelter from rain bearing easterly winds is provided.

\section{Southerly type (Fig. 5c)}

Southerly type circulations result from the presence of blocking anticyclones over central and northern Europe. Atlantic depressions therefore come to a halt west of Ireland and frontal disturbances in association with them may cross Ireland from south to north. A further rain producing mechanism may be envisaged in summer due to the heating of the moist maritime tropical airstream once it crosses on to land.

Overall, this is the circulation type which produces the greatest daily rainfall totals. In the south of Ireland, in particular, amounts may be twice as much as with westerly or cyclonic circulations. Almost everywhere mean daily totals in excess of $3 \mathrm{~mm}$ are experienced, and much higher falls, over $9 \mathrm{~mm}$, are in evidence in the Cork/Kerry area. The driest areas lie on the east coast north of the Wicklows. A very striking gradient exists between Dublin Airport and Valentia with this airflow type.

\section{Unclassified type (Fig. 5d)}

Days when the circulation did not match any of Lamb's criteria for his seven principal or nineteen hybrid types were alloted to this category. Often the synoptic situation was highly complex.

Such days can be seen to provide a substantive amount of precipitation with some distinctive regional variations. Overall the pattern resembles that for the southerly type, as was noted by Houghton and O'Cinneide (1976a) who suggested that a tendency for a southerly airflow might characterize many of these occasions. In a further study the same authors (Houghton and O'Cinneide, 1976b) analyzed six storms yielding over $50 \mathrm{~mm}$ of rainfall. They found in all cases, except one, that the upper airflow was highly meridional, and that such storms tended to be unclassifiable in Lamb's scheme. Much of the pattern for this category may therefore result from slow moving or quasi stationary fronts in association with a southerly airstream.

A number of points emerge from this examination of daily precipitation averages with circulation type. First, despite its relatively small size, Ireland exhibits marked regional contrasts with specific airflow types. Southerly, westerly, and north westerly airflows are particularly significant in producing westeast contrasts, which are often further exacerbated by topographical effects. Cyclonic and anticyclonic circulations on the other hand promote a more even receipt.

Secondly, heaviest falls are associated with a southerly circulation type, and not cyclonic as claimed by Houghton and O'Cinneide (1976a) on the basis of two years of data. This confirms the findings of Mills (1983) who analyzed the decade 1970-79.

Thirdly, it can be hypothesized that the seasonal imbalance in receipt noted may reflect one or both of two possibilities. Either the seasonal frequency of specific circulation types varies, thus providing a greater frequency of wetter/drier airflows at particular times of the year, or seasonal contrasts in yields may exist within particular airflow types. Daultrey (1984) considered the former hypothesis unlikely and so the latter is investigated here. 
The Lamb classification is in effect a means of removing temperature considerations from the more common air mass analysis approach. As such, it has the disadvantage of blurring seasonal differences within circulation types which may arise from thermal controls on the air mass associated with them. Certainly, as Gregory (1964) noted, the classification omits the whole concept of the intensity of development of the circulation system concerned, and this may be an important consideration at a seasonal level.

TABLE III. Seasonal precipitation and principal Lamb types

\begin{tabular}{|c|c|c|c|c|}
\hline \multirow{2}{*}{$\begin{array}{l}\text { Lamb weather } \\
\text { types }\end{array}$} & \multicolumn{4}{|c|}{ Mean daily precipitation $(\mathrm{mm})$ all stations } \\
\hline & Spring & Summer & Autumn & Winter \\
\hline Anticyclonic & 0.81 & 0.94 & $1 \cdot 07$ & $1 \cdot 40$ \\
\hline Cyclonic & 3.53 & $3 \cdot 64$ & $4 \cdot 86$ & $4 \cdot 20$ \\
\hline Westerly & 3.53 & 3.06 & $4 \cdot 27$ & $4 \cdot 26$ \\
\hline North westerly & $1 \cdot 42$ & $1 \cdot 13$ & $2 \cdot 14$ & $2 \cdot 37$ \\
\hline Northerly & 1.01 & 0.73 & 0.99 & $1 \cdot 33$ \\
\hline Easterly & $1 \cdot 47$ & $2 \cdot 32$ & $2 \cdot 70$ & $1 \cdot 78$ \\
\hline Southerly & $4 \cdot 18$ & 3.92 & $5 \cdot 70$ & $5 \cdot 25$ \\
\hline
\end{tabular}

Table III shows the mean precipitation values disaggregated by season. In each case receipts are heaviest in the autumn/winter wetter half of the year and in each season southerly airflows are wettest. Only small seasonal contrasts are in evidence with anticyclonic and northerly flows and the main seasonal differentiation is attributable to the other types. The southerly maximum in autumn is particularly striking and seems related to sea surface temperatures, which are at a maximum in early autumn. In fact the general level of enhancement for most categories is relatively consistent, implying the operation of an outside control, such as sea surface temperature, as the major determinant of rainfall receipt. The role of a warm ocean, transferring latent energy to the air and to cyclonic systems in it, may be inferred from Table III as the major cause of the autumn/winter precipitation maximum in most of Ireland.

Fourthly, it may be suggested that the annual precipitation map of Ireland is essentially a compendium of these daily averages and reflects the frequency of occurrence of individual circulation types in the course of thirty years. It is apparent, therefore, that changes in the mix of circulation types which occur over time will conceivably alter the annual rainfall map to some degree.

\section{THE SIGNIFICANCE OF CIRCULATION CHANGES}

Over the period 1881-1984 the seven basic Lamb types, plus the unclassified category, accounted for 70 per cent of the daily weather patterns over Ireland, the remainder being attributable to the hybrid circulation categories. Anticyclonic, cyclonic and westerly types are dominant in this 70 per cent and clearly Irish rainfall patterns are primarily determined by precipitation received from the last two types, which account for about 66 per cent of annual rainfall throughout Ireland. Changes in the

TABLE IV. Frequency occurrence of Lamb weather types

\begin{tabular}{|c|c|c|}
\hline \multirow{2}{*}{$\begin{array}{l}\text { Lamb type } \\
\text { Anticyclonic }\end{array}$} & \multicolumn{2}{|c|}{$\begin{array}{c}\text { Percentage occurrence } \\
1861-1960 \quad 1961-1984\end{array}$} \\
\hline & $18 \cdot 0$ & $18 \cdot 1$ \\
\hline Cyclonic & $12 \cdot 4$ & $14 \cdot 4$ \\
\hline Westerly & $19 \cdot 5$ & $15 \cdot 2$ \\
\hline North Westerly & $3 \cdot 6$ & $5 \cdot 0$ \\
\hline Northerly & $4 \cdot 7$ & $4 \cdot 6$ \\
\hline Easterly & $3 \cdot 4$ & $4 \cdot 1$ \\
\hline Southerly & $4 \cdot 2$ & $4 \cdot 4$ \\
\hline Unclassified & $3 \cdot 3$ & $4 \cdot 9$ \\
\hline Anticyclonic N.E. & $1 \cdot 4$ & $1 \cdot 4$ \\
\hline Anticyclonic E. & $2 \cdot 6$ & $2 \cdot 2$ \\
\hline Anticyclonic S.E. & 0.9 & $1 \cdot 0$ \\
\hline Anticyclonic S. & $1 \cdot 1$ & $1 \cdot 0$ \\
\hline Anticyclonic S.W. & $0 \cdot 7$ & $1 \cdot 0$ \\
\hline Anticyclonic W. & $4 \cdot 9$ & $4 \cdot 0$ \\
\hline Anticyclonic N.W. & $1 \cdot 5$ & $1 \cdot 6$ \\
\hline Anticyclonic N. & $2 \cdot 1$ & $2 \cdot 0$ \\
\hline \multicolumn{3}{|l|}{ All Anticyclonic } \\
\hline sub categories & $15 \cdot 2$ & $14 \cdot 2$ \\
\hline North Easterly & 0.9 & $1 \cdot 1$ \\
\hline South Easterly & $1 \cdot 6$ & $2 \cdot 0$ \\
\hline South Westerly & $2 \cdot 5$ & $3 \cdot 2$ \\
\hline Cyclonic N.E. & 0.3 & 0.5 \\
\hline Cyclonic E. & $1 \cdot 0$ & $1 \cdot 3$ \\
\hline Cyclonic S.E. & 0.5 & $0 \cdot 4$ \\
\hline Cyclonic S. & $1 \cdot 3$ & $1 \cdot 1$ \\
\hline Cyclonic S.W. & 0.7 & 0.5 \\
\hline Cyclonic W. & $4 \cdot 4$ & $2 \cdot 7$ \\
\hline Cyclonic N.W. & 0.9 & $1 \cdot 0$ \\
\hline Cyclonic N. & $1 \cdot 3$ & $1 \cdot 5$ \\
\hline All Cyclonic & & \\
\hline sub categories & $10 \cdot 4$ & $9 \cdot 0$ \\
\hline
\end{tabular}




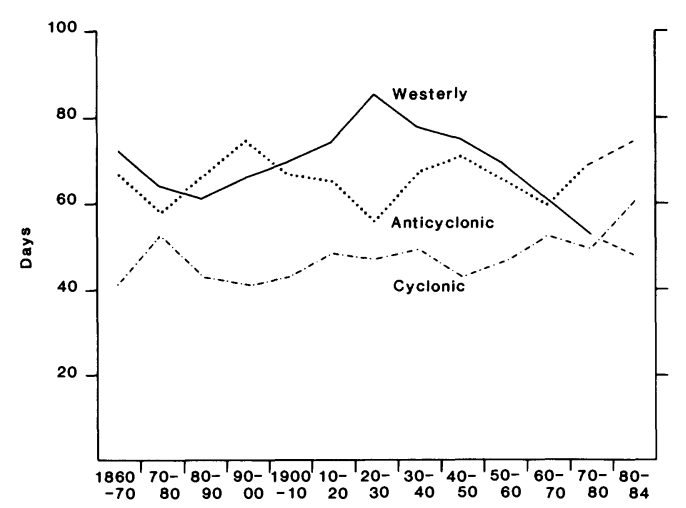

FIGURE 6. Decadal averages of principal Lamb types

cyclonic/westerly relationship are thus potentially of significance for the national pattern.

Table IV shows that, in terms of circulation frequencies, the period 1961-84 differs in some key respects from the previous 100 year averages. A 2 per cent increase in cyclonicity, and a 1.4 per cent

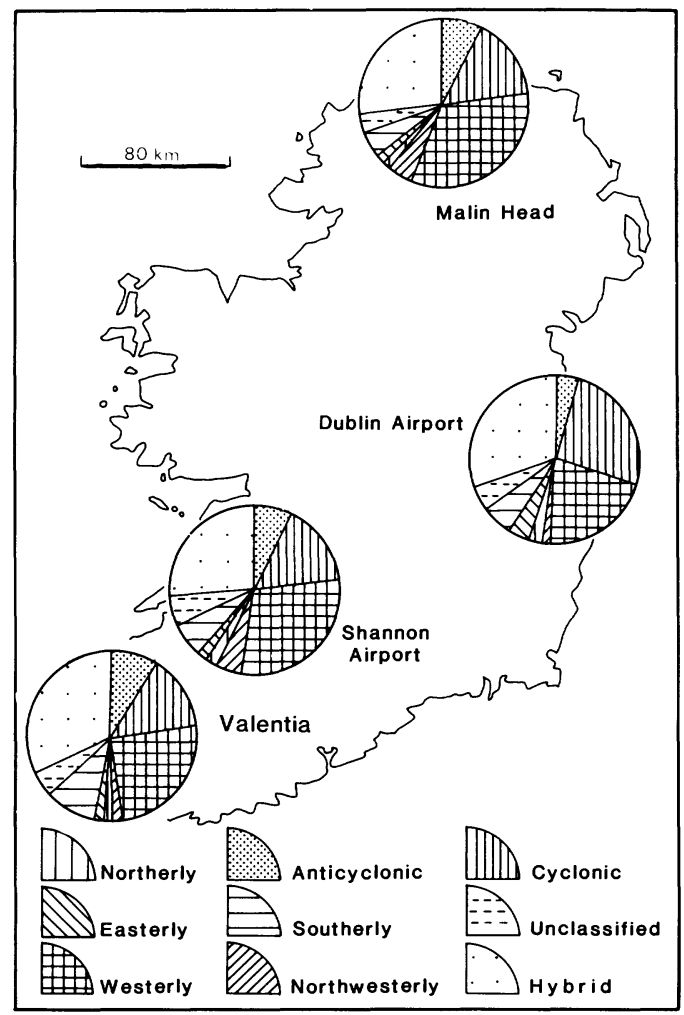

FIGURE 7. Contribution to annual total by Lamb categories, 1861-1960 increase in north westerly weather can be noted. The major feature, however, is the large fall in westerly days. Only slight changes in the other categories are apparent, and since these contribute only small amounts to the annual total precipitation, they are not so significant.

These changes are well documented. Sowden and Parker (1981) have suggested that April and August westerlies have undergone significant changes in their frequency over the past 120 years while Jones and Kelly (1982) noted that:

... a marked shift towards cyclonic conditions (since the 1950s) had occurred at the expense of westerliness and anticyclonicity.

These trends are clearly depicted in Figure 6. The substantial reduction in the number of westerly days from over 80 per year in the 1940 s to around 50 in the 1970s is particularly striking and has been linked to changing vigour in the global circulation at large. A slight southerly displacement of the circumpolar

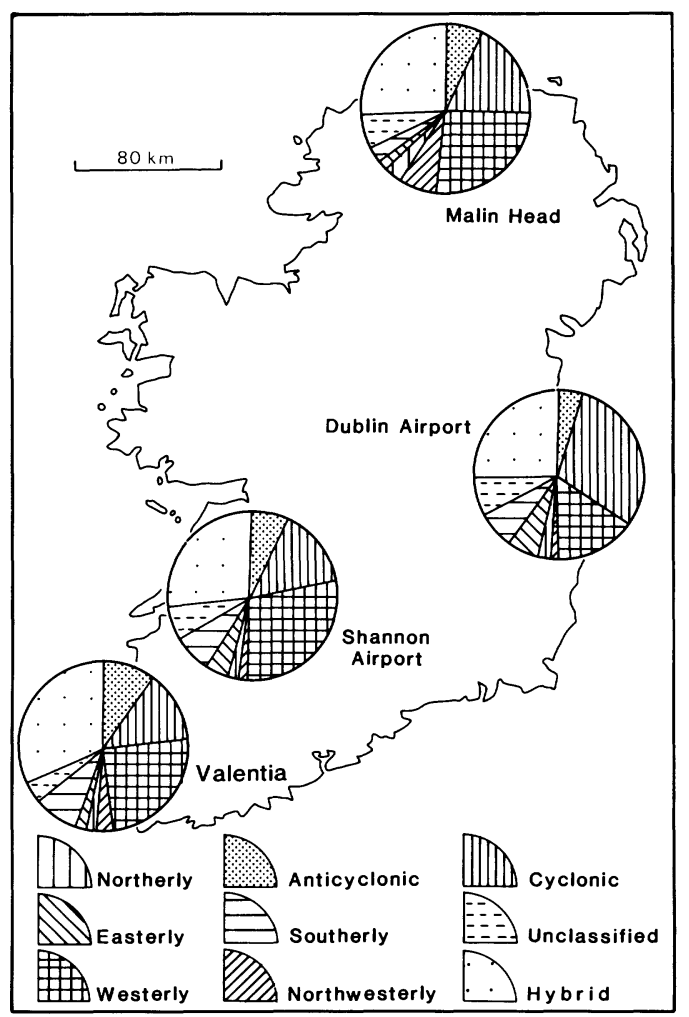

FIGURE 8. Contribution to annual total by Lamb categories, 1961-1984 


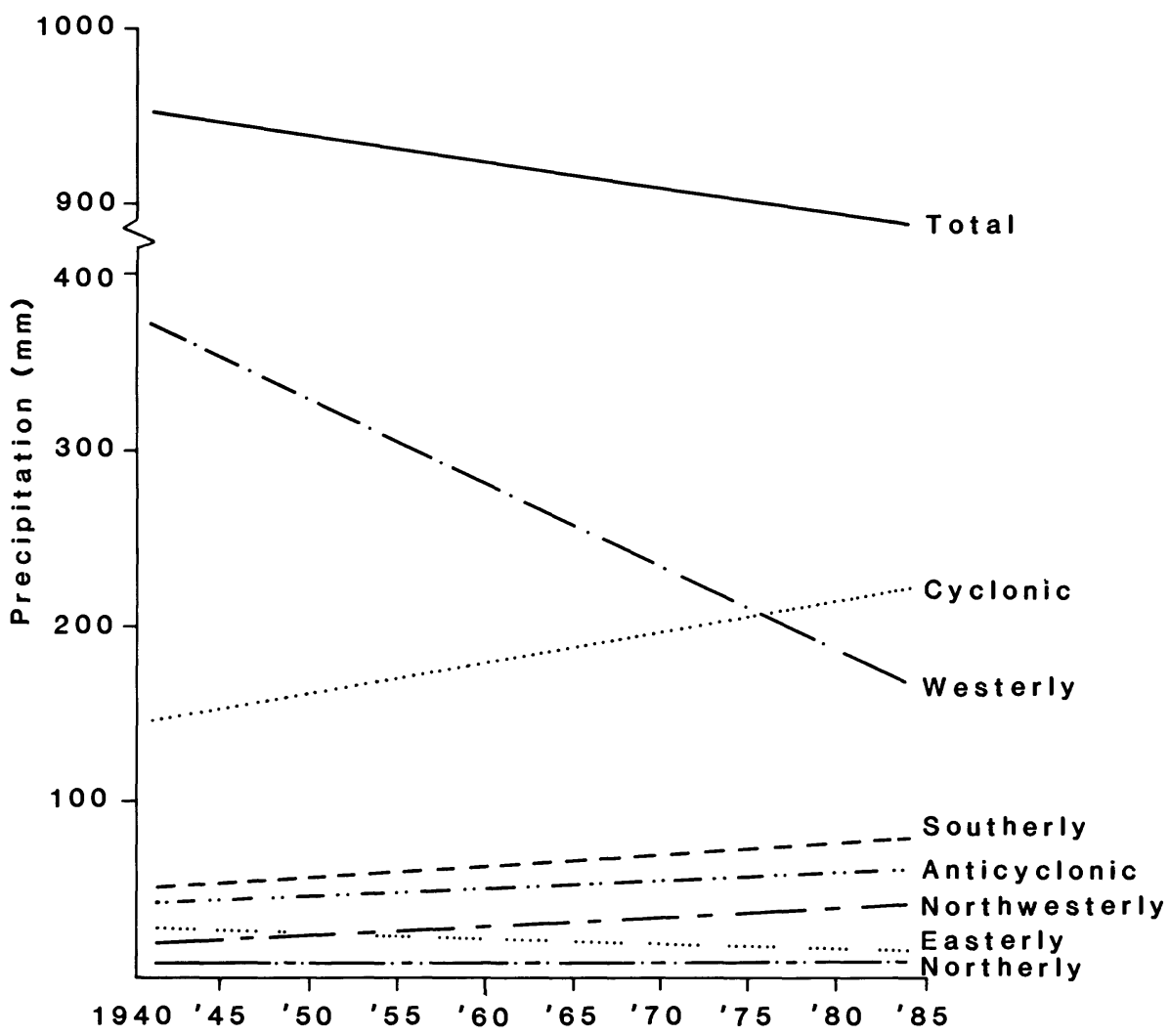

FIGURE 9. Simple linear trend in precipitation receipt, annually, and by principal Lamb types-Shannon Airport

vortex would bring depression tracks closer to Ireland and simultaneously increase cyclonicity. The diminishing westerly circulation has also been linked to a decline in northern hemisphere mean temperature and to rainfall changes in the Sahel (Lamb, 1982).

The impact of these changes on Irish rainfall patterns can best be appreciated if the makeup of precipitation receipt over two contrasting time periods is examined. Figure 7 shows the relative contribution by circulation type to overall amounts at Valentia, Shannon, Dublin and Malin Head based on the 100 year average 1861-1960. For both Valentia and Shannon westerly rainfall is about twice as important as cyclonic. In the case of Shannon, westerly rainfall is by far the dominant proportion. Southerly and hybrid contributions are obviously restricted in their yield by the shelter effects of surrounding uplands. At Dublin Airport roughly equal contributions from cyclonic and westerly sources may be noted.
The same breakdown for 1961-84 (Fig. 8) shows considerable differences. In each case the importance of the westerly source has greatly diminished. At Valentia and Shannon it is only slightly greater than cyclonic, while at Dublin, cyclonic is almost twice as important as the westerly type.

The impact of such changes on total rainfall amount may vary from place to place. Over most of Ireland declining contributions from westerly sources have been compensated for by increases in rainfall from the other sources, particularly cyclonic or some of the hybrid categories. The long term trend in rainfall may therefore be unchanged. In some instances, however, the airflows which replace the westerlies are significantly drier and the long term trend may show a slight decline. This appears to be happening at Shannon where, because of the area's unusually high dependance on westerly rainfall, its vulnerability to a decline is greatest. The relief configuration of the area around Shannon renders it less exposed to rainfall from other direc- 


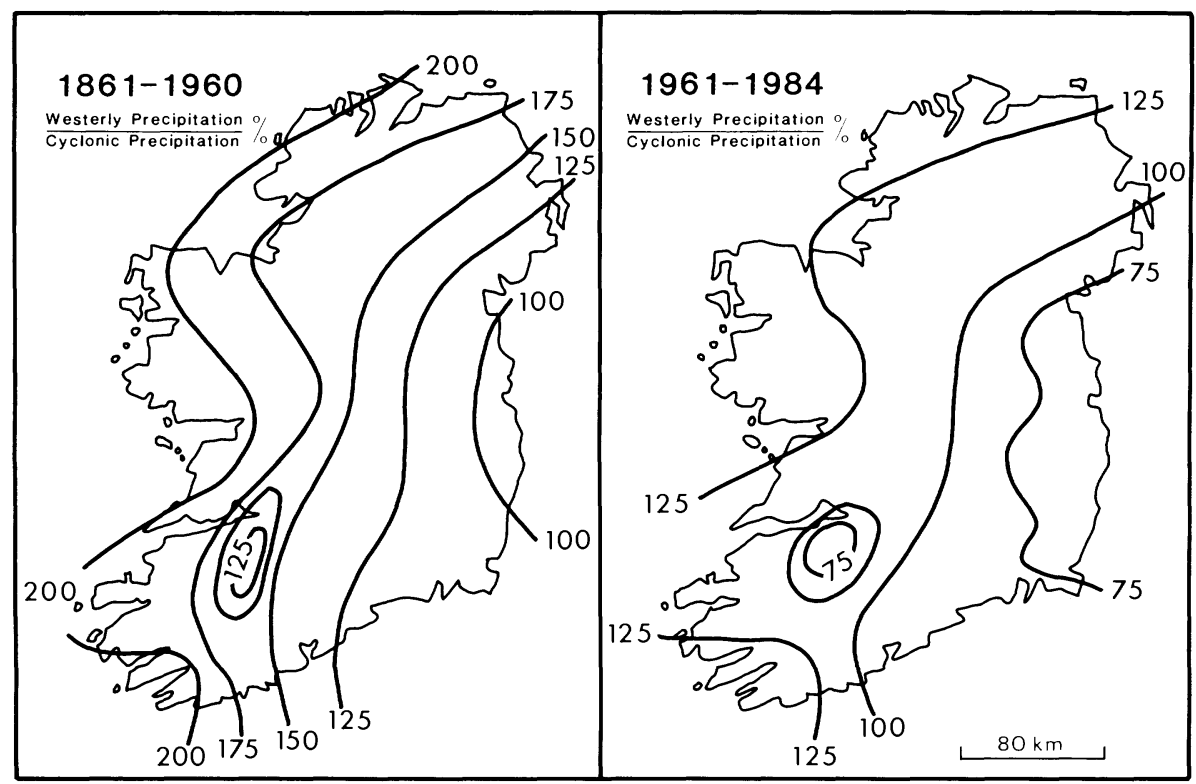

FIGURE 10. Precipitation received from westerly circulation types as a percentage of that received from cyclonic types $\begin{array}{ll}\text { (a) 1861-1960 } & \text { (b) 1961-1984 Regime }\end{array}$

tions. An increased frequency of these airflows has not therefore been sufficient to compensate for the westerly decline and a slight negative trend in annual rainfall receipt is apparent (Fig. 9).

A second set of impacts relates to the geographical distribution of annual precipitation. This stems principally from the replacement of precipitation derived from westerly sources by that derived with cyclonic circulation type. Figure 10a shows the ratio of westerly to cyclonic rainfall based on the hundred year circulation averages and the mean rainfall with each circulation type already derived. Only along the eastern coastline is there a dominantly cyclonic regime. Elsewhere westerly rainfall is much more important, almost twice as much along the north western seaboard. This changes considerably during the period 1960-1984 (Fig. 10b). For this period half of the island falls into each category. The continuation of these trends means that at present, at all locations in Ireland, even on the extreme west coast, cyclonic rainfall is now probably an equal, if not greater, contributor to annual totals than westerly rainfall. The significance of this can be assessed by remembering the spatial differences which were apparent with these two circulation types. Cyclonic rainfall showed little spatial variation, while westerly rainfall produced the west east gradient observed on the annual map. Thus it seems possible that a blurring of west-east contrasts may be a consequence of these changes in circulation frequencies. At present this seems to be being masked by increases in rainfall from a combination of other sources and the role of these less frequent circulation types therefore requires further study. The continued growth of cyclonic rainfall at their expense may, however, make discernible changes on the 1961-90 map of annual receipt.

\section{CONCLUSIONS}

The annual precipitation regime of Ireland shows the effects of complex contributions from a variety of circulation types. Some of these promote marked geographical variations in receipt, related to the influence of trajectory, orographic considerations and the role of sea surface temperatures. Changes in the frequency of these circulation types are occurring. The effect of these is to alter the proportion of rainfall received from particular circulation types over time with possible ramifications for long term trends at some locations and for the classic west-east gradient of rainfall in Ireland in the future. 


\section{ACKNOWLEDGEMENTS}

I would like to express my gratitude to the Irish Meteorological Service, in particular $\mathrm{Mr}$ Denis Fitzgerald and $\mathrm{Mr}$ Andy McManus, for generously making available all rainfall data relating to the Republic of Ireland to me.

\section{REFERENCES}

BETTS, N. L. (1982) 'Climate: a synoptic climatology of Northern Ireland', in: CRUICKSHANK, J. G. and WILCOCK, D. N. (eds), Northern Ireland: Environment and Resources, (Belfast) pp. 9-42

BLEASDALE, A. (1963) 'The distribution of exceptionally heavy falls of rain in the United Kingdom', J. Instn. Wat. Engrs. 17: 45-55

DAULTREY, S. (1984) 'Climatology', Ir. Geogr. (Jubilee Vol.) pp. 117-28

DIXON, F. E. (1955) Extremes of precipitation in periods of consecutive months Tech. Note 19, Ir. Met. Ser., (Dublin)

GLASSPOOLE, J. (1930) "The areas covered by intense and widespread falls of rain', Proc. Instn. Civil Engrs. 229: sess. 1929-30, Part 1

GREGORY, S. (1964) 'Climate', in: WATSON, J. W. and SISSONS, J. B. (eds), The British Isles: A systematic geography, (London) pp. 53-73

HOBBS, P. V. and LOCATELL, J. D. (1978) 'Rainbands, precipitation cores and generating cells in a cyclonic storm', J. Atmos. Sci. 35: 230-41

HOUGHTON, J. G. and O'CINNEIDE, M. (1976a) 'Synoptic origin of Irish precipitation 1970-71', Weather 31: 11-25

HOUGHTON, J. G. and O'CINNEIDE, M. (1976b) 'Distribution and synoptic origin of selected heavy precipitation storms over Ireland', Ir. Geogr. 9: 1-8
JONES, P. D. and KELLY, P. M. (1982) 'Principal component analysis of the Lamb catalogue of daily weather types: part 1 annual frequencies, J. Climatology 2: 147-57

LAMB, H. H. (1950) 'Types and spells of weather around the year in the British Isles: annual trends, seasonal structure of the year, singularity', Q. J. R. Met. S. 76: 393-438

LAMB, H. H. (1972) 'British Isles weather types and a register of the daily sequence of circulation patterns 1861-1971', Geophys. Memo. 16, (London)

LAMB, H. H. (1982) Climate, history and the modern world, (London)

LOGUE, J. J. (1971) Rain-intensity-amount-frequency relationships in Ireland Tech. Note 34, Ir. Met. Ser., (Dublin)

LOGUE, J. J. (1975) Extreme rainfalls in Ireland Tech. Note 40, Ir. Met. Ser., (Dublin)

LOGUE, J. J. (1978) The annual cycle of rainfall in Ireland Tech. Note 43, Ir. Met. Serv., (Dublin)

METEOROLOGICAL OFFICE (1975) 'Estimated maximum falls of rain', Flood Stud. Rep. 2: 33-7

MILLS, G. (1983) The synoptic origins and spatial distributions of Irish precipitation 1970-79, Unpub. M. A. thesis, Dept. of Geography, Univ. College Dublin

MORGAN, W. A. (1953) 'The frequency of heavy daily rainfalls in Ireland', Geophys. Publ. 4(1), Ir. Met. Ser., (Dublin)

PERRY, A. H. (1972) 'Spatial and temporal characteristics of Irish precipitation', Ir. Geogr. 5: 428-42.

ROHAN, P. K. (1975) The climate of Ireland, (Dublin)

SOWDEN, I. P. and PARKER, D. E. (1981) 'A study of climatic variability of daily central England temperatures in relation to the Lamb synoptic types', J. Climatology 1: 3-10

THOMAS, T. M. (1960) 'Some observations on the tracks of depressions over the eastern half of the North Atlantic', Weather 15: 325-60 